\title{
Uterine Injury Caused by Genotype 4 Hepatitis E Virus Infection Based on a BALB/c Mice Model
}

\author{
Weimin Yang ${ }^{1,+}$, Shuangfeng Chen ${ }^{1,+}$, Houfack K. Mickael ${ }^{1}$, Liangheng Xu ${ }^{1} \mathbb{D}$, Yueping Xia ${ }^{1}$, Chao Cong $^{1}$, \\ Yike Zhang ${ }^{1}$, Zhongyao Qian ${ }^{1}$, Tengyuan Li $^{1}$, Daqiao Wei ${ }^{1}$, Wenhai $\mathrm{Yu}^{2}$ and Fen Huang ${ }^{1,3, *(\mathbb{D})}$ \\ 1 Medical Faculty, Kunming University of Science and Technology, Kunming 650500, China; \\ yangweimin7777@163.com (W.Y.); csf521csy6688@163.com (S.C.); houfack@gmail.com (H.K.M.); \\ heng1178@163.com (L.X.); xyp68995@163.com (Y.X.); cc18469171503@163.com (C.C.); \\ zhangyike77332@163.com (Y.Z.); qianzhongyao96@163.com (Z.Q.); ltylitengyuan@163.com (T.L.); \\ weidaqiao1234@kmust.edu.cn (D.W.) \\ 2 Institute of Medical Biology, Chinese Academy of Medical Sciences and Peking Union Medical College, \\ Kunming 650038, China; wenhaiyu1234@163.com \\ 3 Yunnan Provincial Key Laboratory of Clinical Virology, Kunming 650034, China \\ * Correspondence: huangfen6789@163.com \\ + These authors contribute equally to this study.
}

check for updates

Citation: Yang, W.; Chen, S.; Mickael, H.K.; Xu, L.; Xia, Y.; Cong, C.; Zhang, Y.; Qian, Z.; Li, T.; Wei, D.; et al. Uterine Injury Caused by Genotype 4 Hepatitis E Virus Infection Based on a BALB/c Mice Model. Viruses 2021, 13 , 1950. https://doi.org/10.3390/ v13101950

Academic Editors: Edwin Leeansyah and Liyen Loh

Received: 27 August 2021

Accepted: 23 September 2021

Published: 28 September 2021

Publisher's Note: MDPI stays neutral with regard to jurisdictional claims in published maps and institutional affiliations.

Copyright: (c) 2021 by the authors. Licensee MDPI, Basel, Switzerland. This article is an open access article distributed under the terms and conditions of the Creative Commons Attribution (CC BY) license (https:// creativecommons.org/licenses/by/ $4.0 /)$

\begin{abstract}
To evaluate whether uterine injury caused by hepatitis E virus (HEV) infection is responsible for adverse pregnancy outcomes. HEV-infected female BALB/c mice were coupled with healthy male BALB/c mice at $0,7,14,21$, and 91 dpi to explore the uterine injury caused by HEV infection. Mice were euthanized after 10 days of copulation, and uteruses were collected for HEV RNA and antigen detection and histopathological analysis. Inflammatory responses; apoptosis; and estrogen receptor $\alpha$ (ER- $\alpha)$, endomethal antibody (ERAb), cytokeratin-7 (CK7), vimentin (VIM), and vascular endothelial growth factor (VEGF) expression levels were evaluated. After 10 days of copulation, miscarriage and nonpregnancy, as well as enlarged uteruses filled with inflammatory cytokines, were found in HEVinfected mice. HEV RNA and antigens were detected in the sera and uteruses of HEV-infected mice. Significant endometrial thickness (EMT) thinning, severe inflammatory responses, and aggravated apoptosis in the uteruses of HEV-infected mice that experienced miscarriage might contribute to adverse pregnancy outcomes. Furthermore, significantly suppressed ER- $\alpha$ expression and increased ERAb, CK7, VIM, and VEGF expression levels were found in the uteruses of HEV-infected mice that had miscarried. However, uterine damage recovered after complete HEV clearance, and impaired fertility was improved. EMT injury, severe inflammatory responses, and aggravated apoptosis in the uterus caused by HEV infection are responsible for poor pregnancy outcomes.
\end{abstract}

Keywords: hepatitis E virus; pregnancy; uterine injury; miscarriage

\section{Introduction}

Hepatitis E virus (HEV) is one of the most common causes of acute hepatitis worldwide. It results in 20 million infections and 70,000 related deaths every year [1-3]. HEV genotype 1 and 2 infections cause large outbreaks and affect young subjects with a significant mortality rate in pregnant women and patients with cirrhosis in developing countries [4], while genotype 3 and 4 infections are responsible for sporadic and zoonotic diseases and are mainly transmitted by consumption of undercooked meat or milk in developed countries [5-7]. HEV infection is usually self-limiting and has a mortality of $<1 \%$ in the general population [8]. However, genotype $1 \mathrm{HEV}$ infection during pregnancy often results in fulminant hepatic failure (FHF) and leads to a maternal death rate of $>25 \%$ [9]. Severe adverse pregnancy outcomes, including maternal death, premature delivery, abortion, and stillbirth, induced by HEV have been reported in the clinic [10,11]. Genotype $3 \mathrm{HEV}$ infections are known to be less pathogenic at the maternal-fetal interface [12]. However, severe symptoms were induced by genotype $4 \mathrm{HEV}$ infections [13]. Stillbirth, threatened 
preterm births, and abortion caused by HEV infection have been reported recently in China, where genotype $4 \mathrm{HEV}$ is prevalent $[14,15]$.

However, the pathogenesis of HEV infection during pregnancy is unclear. Extremely elevated estrogen and progesterone levels have been found in HEV-infected pregnant women $[16,17]$. The increase in hormones, especially estrogen, during pregnancy facilitates HEV replication through inhibition of the PI3K-AKT-mTOR and cAMPK-PKA-CREB signaling pathways [17,18]. Furthermore, the suppression of estrogen and progesterone receptors are associated with HEV replication during pregnancy $[16,18,19]$. In addition, the innate immunity of pregnant women shows increased sensitivity to HEV infection as reflected by elevated viral titers and prolonged viral infection duration [20]. Retinoic acid induces gene protein I (RIG-I), the most critical antiviral interferon-stimulated gene, is severely frustrated and is inhibited by $7460.70 \pm 3421.28$-fold in HEV-infected pregnant rhesus macaques relative to in nonpregnant rhesus macaques; this condition may be responsible for the impaired innate immune response against viral infection [20]. Disordered hormones, inhibited signal pathways, and frustrated innate immune systems may account for poor pregnancy outcomes.

Vertical transmission from mothers to fetuses is recognized as one of the routes of HEV transmission [20-22]. The uterus is the most important organ for the maintenance of pregnancy. The uterus, especially the endometrium lining, plays an important role in normal reproductive cycles, implantation, and placentation and in supporting a healthy fetus until parturition [23]. Pathogen infection in the uterus usually causes infertility, abortion, preterm delivery, and other clinical diseases [24-27]. The infection of the uterus by viruses, such as porcine reproductive and respiratory syndrome (PRRSV) [28], coxsackievirus B3 (Cvb3) [29], human papillomavirus [30], human cytomegalovirus [31,32], and Zika virus [33], results in adverse pregnancy outcomes. PRRSV replicates in the endometrium of sows and causes endometrial cell apoptosis, consequently leading to miscarriage, stillbirth, premature birth, neonatal death, and fetal hypoplasia [28]. Cvb3 infects the mouse uterus, produces an inflammatory response, and consequently results in spontaneous abortion [29]. Although genotype $4 \mathrm{HEV}$ replication in the uteruses of HEV-infected BALB/c mice has been reported [34], the pathogenic mechanism of HEV infection in the uterus remains undefined.

In this work, genotype $4 \mathrm{HEV}$-infected BALB/c mice were used to mimic HEV infection during pregnancy to evaluate the pathogenesis of HEV infection in the uterus. Interestingly, failed pregnancy was found in most of the genotype $4 \mathrm{HEV-infected} \mathrm{female}$ mice even when they were synchronized with serum gonadotrophinum (PMSG) and chorionic gonadotrophin (HCG). Metritis, intimitis, and endometrium thinning were observed in the genotype $4 \mathrm{HEV}$-infected nonpregnant mice. However, the damages to the uterus recovered after HEV clearance, and impaired fertility partially improved.

\section{Methods}

\subsection{Animal and Ethics Statement}

BALB/c mice (female, 6 weeks old, $n=40$ ) were purchased from Kunming Medical University and bred in a specific-pathogen-free facility at Kunming University of Science and Technology. All operations were performed in accordance with the guidelines of the Kunming University of Science and Technology Animal Care and Use Committee. Mice that were negative for anti-HEV antibodies (IgG and IgM) and HEV RNA were included in this study.

\subsection{Reagents}

PMSG (050074564) and HCG (050071281) were purchased from Chifeng Boen Pharmaceutical Co., Ltd. (Inner Mongolia, China). HEV-specific antibody (MAB8003) was obtained from Millipore (Burlington, MA, USA). Rabbit-anti-CD45+ (A2115) and ERAb (ab170864) were procured from ABclonal (Boston, MA, USA). Vimentin (Vim, D21H3) XP(R) was purchased from Cell Signaling Technology (Boston, MA, USA). Anti-F4/80+ antibody 
(ab6640), anticytokeratin 7 (ab181598), anti-VEGFA (ab1316), antiestrogen receptor alpha antibody (ab108398), and horseradish peroxidase- or fluorescein (FITC)-labeled secondary antibodies were purchased from Abcam (Cambridge, UK).

\subsection{Virus}

HEV genotype 4 (KM01, GenBank No. KJ155502) was collected from a village in Kunming, China. Fecal suspension (10\%) was centrifuged at $12,000 \times g$ and $4{ }^{\circ} \mathrm{C}$ for $10 \mathrm{~min}$, filtered through $0.22 \mu \mathrm{m}$ microfilters, and treated with penicillin and streptomycin for $1 \mathrm{~h}$. The suspension was then stored in liquid nitrogen until use. Viral genomic titers consisting of $1.0 \times 10^{6}$ copies were determined by using quantitative real-time PCR (qRT-PCR) as previously described [35].

\subsection{Cell Cultures and Viral Inoculation}

Hela cells (human cervical cancer cell line) were maintained in Dulbecco's modified Eagle's medium (DMEM) supplemented with $10 \%$ fetal bovine serum at $37{ }^{\circ} \mathrm{C}$ with $5 \%$ $\mathrm{CO}_{2}$. The Hela cells were inoculated with HEV in accordance with our previous report [16]. The cells were harvested for HEV detection through qRT-PCR and immunofluorescence at indicated time points.

\subsection{Experimental Design}

Mice were divided into five groups as shown in Figure 1. The mock group $(n=12)$ consisted of 12 mice. In the mock group, four mice that were coupled with healthy adult male mice served as the pregnancy control; four mice that were synchronized with PMSG and HCG by intramuscular injection after $24 \mathrm{~h}$ served as the synchronization group; and the remaining four mice that were injected with PBS without copulation served as the mock nonpregnant control. Mice that were intravenously infected with HEV at 7 days postinfection (dpi, $n=8), 14 \mathrm{dpi}(n=8)$, and $21 \mathrm{dpi}(n=8)$ were copulated with healthy adult male mice (1:1) for 10 days or pretreated with PMSG and HCG before 10 days of copulation (E10). Mice in the HEV-cleared group ( $n=4,91 \mathrm{dpi})$, which had been completely cleared of HEV RNA and antigens for at least for 56 days, were copulated with healthy adult male mice (1:1) to assess the effect of HEV infection after viral clearance. Serum samples were collected at 5,8 , and 10 days post-copulation for progesterone determination to identify whether the copulated mouse was pregnant. All mice were humanely euthanized and necropsied after 10 days of copulation (E10). Sera, spleens, and uteruses were collected, and the uteruses were fixed in neutral $4 \%$ paraformaldehyde solution.

\subsection{HEV RNA Detection and Gene Quantification}

Total RNA was extracted from sera, uteruses, or cells by Trizol (Invitrogen, CA, USA) in accordance with the manufacturer's instructions. cDNA was prepared using AMV Reverse Transcriptase XL (Takara, Ibaraki, Japan) as the direction. Reverse transcription PCR was performed at $30^{\circ} \mathrm{C}$ for $10 \mathrm{~min}, 42^{\circ} \mathrm{C}$ for $30 \mathrm{~min}, 99^{\circ} \mathrm{C}$ for $5 \mathrm{~min}$, and $5{ }^{\circ} \mathrm{C}$ for $5 \mathrm{~min}$. The genomic copy number of HEV was quantified using SYBR green-based qRT-PCR with HEV-specific primers as described in a previous study [5]. qRT-PCR was performed in the Bio-Rad CFX96TM Real-Time PCR System. GAPDH served as a loading control.

\subsection{Morphological and Histopathological Analyses}

Tissues for histopathological examination were fixed in $10 \%$ neutral buffered formalin, routinely processed, sectioned to a thickness of $3 \mu \mathrm{m}$, and then stained with hematoxylin and eosin (H\&E). The samples were photographed and analyzed by using a microscope (Nikon, Tokyo, Japan) equipped with a digital camera. 


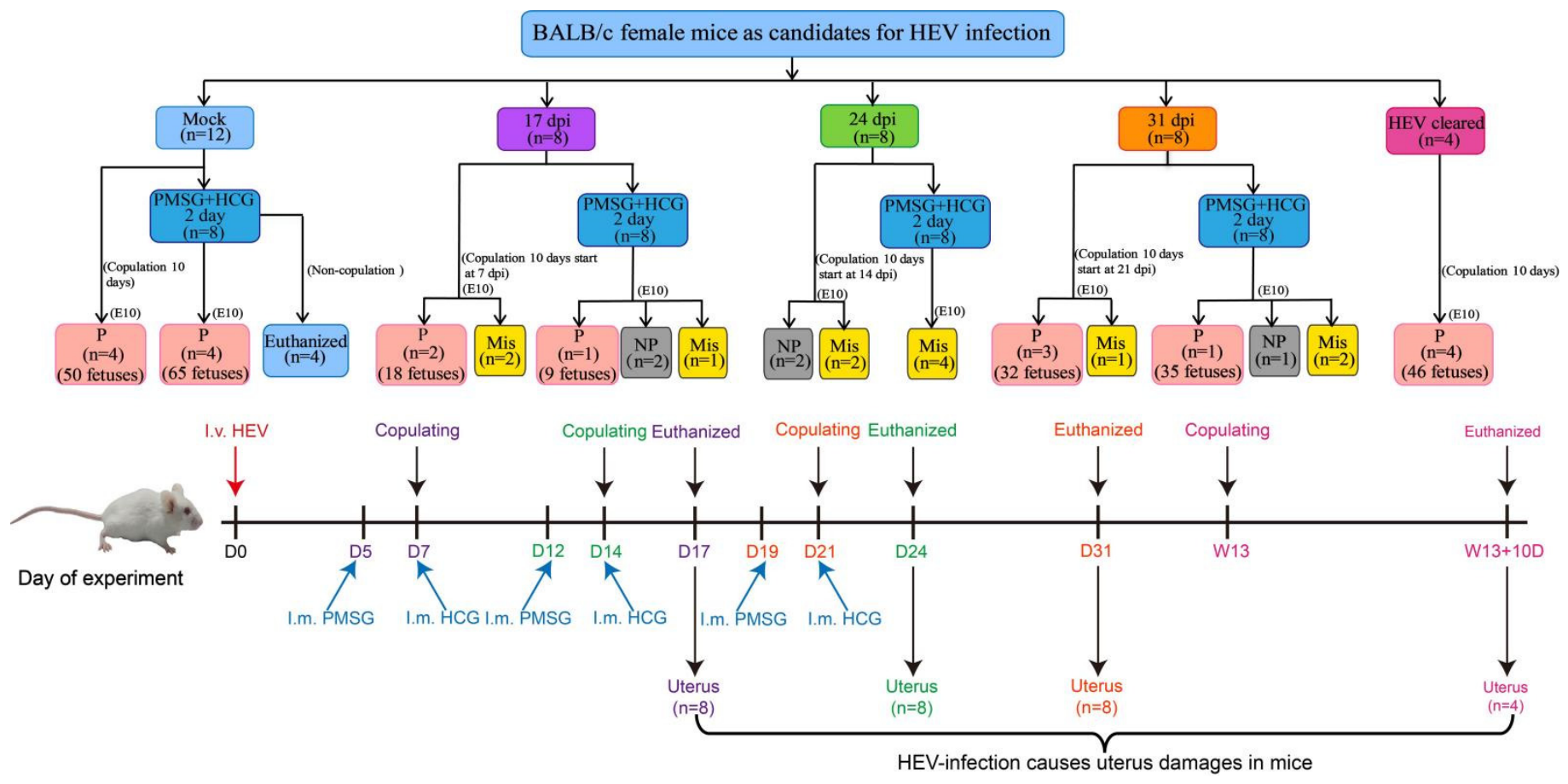

Figure 1. Diagram of HEV infection in female mice. P, pregnant; NP, nonpregnant; Mis, miscarried.

\subsection{Immunohistochemistry and Immunofluorescence}

The tissue sections for immunohistochemical analysis (IHC) and immunofluorescence assay (IFA) were treated with $3 \% \mathrm{H}_{2} \mathrm{O}_{2}$ for 10 min and blocked with $5 \%$ skimmed milk for $30 \mathrm{~min}$. The sections were incubated with the indicated antibody at $4{ }^{\circ} \mathrm{C}$ overnight. After three cycles of washing with PBS, the sections were incubated with the secondary antibody as described in our previous report [36]. The tissue sections were viewed by using fluorescence microscopy (Nikon Ti-E, Tokyo, Japan).

For the IFA of cell cultures, the cells were fixed for $15 \mathrm{~min}$ with $4 \%$ paraformaldehyde at $48 \mathrm{~h}$ postinfection, incubated for $1 \mathrm{~h}$ at $37^{\circ} \mathrm{C}$ with an HEV-specific antibody (MAB8003, Millipore, America), then inoculated with FITC-conjugated secondary antibodies for $45 \mathrm{~min}$ at room temperature. The cells were stained with DAPI for $15 \mathrm{~min}$ and viewed under a fluorescence microscope (Nikon Ti-E, Tokyo, Japan).

\subsection{Terminal Deoxynucleotidyl Transferase dUTP Nick end Labeling Assay}

Apoptotic cells in the uterus were evaluated in situ by using a One Step terminal deoxynucleotidyl transferase-mediated dUTP nick-end labelling (TUNEL) assay kit (Beyotime, C1086). Briefly, the tissue sections were deparaffinized, rehydrated, and then digested with DNase and proteinase $\mathrm{K}(20 \mu \mathrm{g} / \mathrm{mL})$ for $30 \mathrm{~min}$ at $37^{\circ} \mathrm{C}$. The slides were incubated with the TUNEL detection kit for $60 \mathrm{~min}$ at $37^{\circ} \mathrm{C}$. Nuclei were counterstained with DAPI. Then, the TUNEL specimens were observed under a fluorescence microscope (Nikon Ti-E, Tokyo, Japan).

\subsection{Statistical Analysis}

All experiments were performed at least three times. Statistical analysis was performed by using IBM SPSS Statistics 21 software. The density of positive signals/bands of IHC or Western Blot was measured by Image-Pro Plus 6.0 software. Student's $t$-test was performed to analyze the significance of differences between two groups: ${ }^{*} p<0.05$; ${ }^{* *} p<0.01 ;{ }^{* * *} p<0.001$. 


\section{Results}

\subsection{HEV Replicates in the Uterus}

BALB/c mice with acute HEV infection were copulated with healthy male mice to evaluate the uterine injury caused by HEV infection and to investigate the pathogenesis of HEV infection in the uterus. The serum of all mice inoculated with HEV were positive for HEV RNA from 7 to 48 dpi (Figure 2A). Notably, HEV RNA was detected in the uteruses of HEV-infected mice with considerable serum viral titers (Figure 2B). This result indicated that HEV replicates in the uteruses of female mice. However, the sera and uteruses from mock mice were negative for HEV RNA. The uterus provides a safe space and adequate nutrition for fetal development and pregnancy maintenance [37]. IHC and IFA revealed the presence of HEV antigens in the uteruses of HEV-infected mice at 17, 24, and 31 dpi (Figure 2C,D). These results strongly demonstrated that the uterus is a replication site of HEV. Interestingly, HEV antigens mainly accumulated in the endometrium of infected mice.
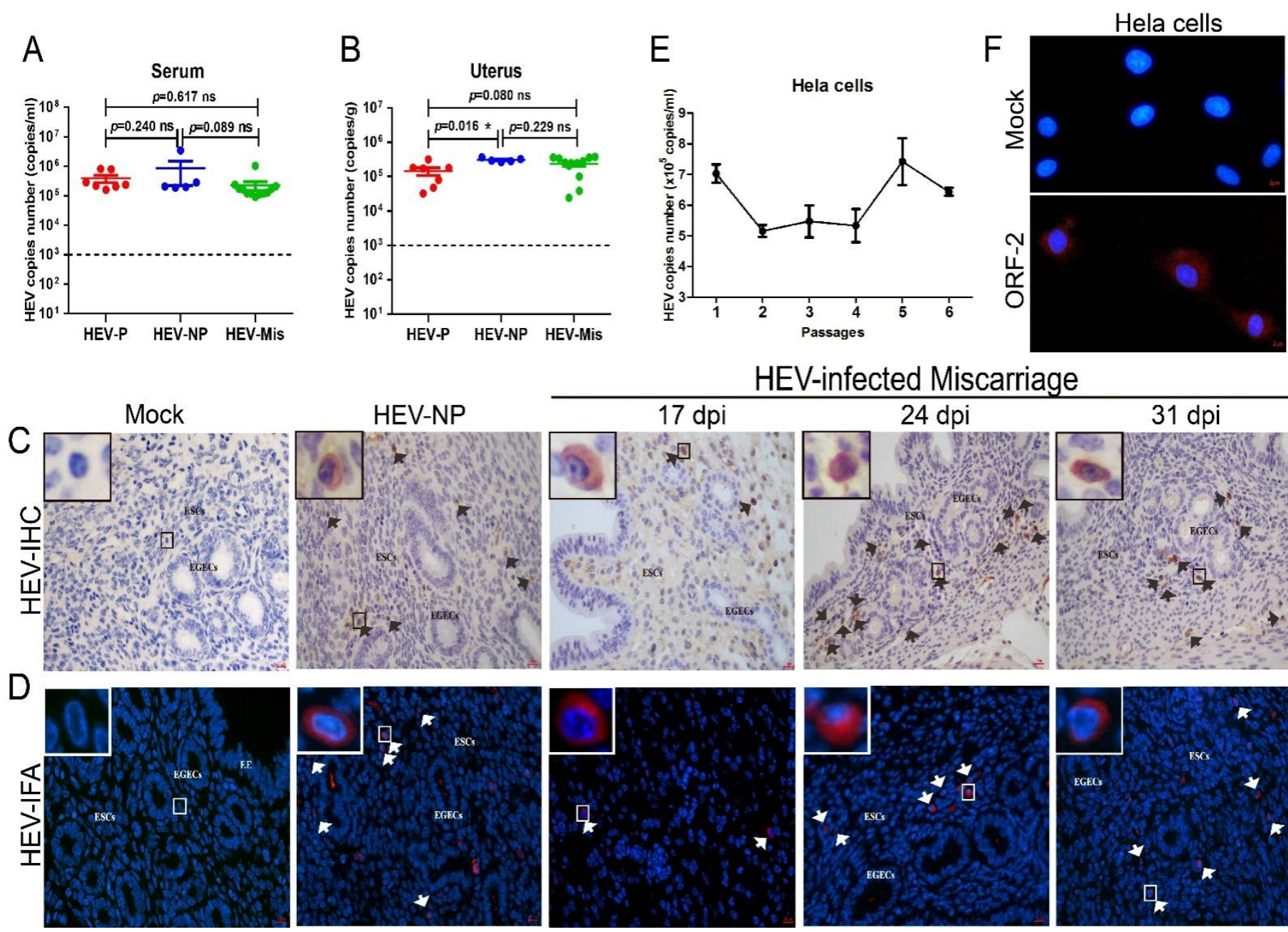

HEV-infected Miscarriage

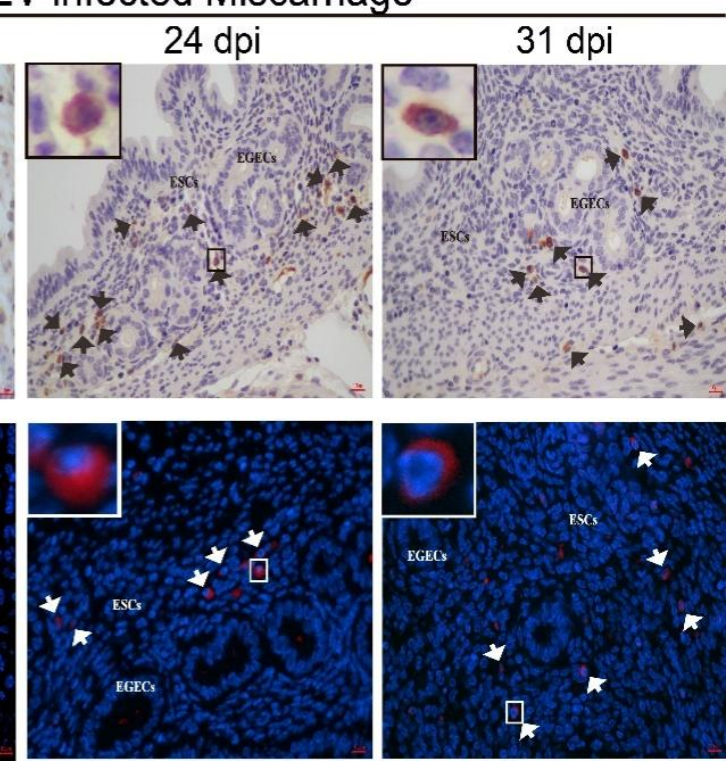

Figure 2. HEV replicates in the uterus. HEV RNA detected in the serum (A) and uterus (B) of HEV-infected mice and quantitated by qRT-PCR. The copy numbers of HEV RNA in the serum and uterus were compared and analyzed by using IBM SPSS Statistics 21 software. ${ }^{*} p<0.05$. HEV antigens detected in the uteruses of mock or HEV-infected mice by IHC (C) and IFA (D). ESCs: endometrial stromal cells; EGECs: endometrial gland epithelial cells. (E) HEV titer in HEV-inoculated Hela cells determined by qRT-PCR. (F) HEV antigens (red) observed in mock or HEV-infected Hela cells by IFA with a HEV-specific antibody. Nuclei stained by DAPI (blue). 
Hela cells were inoculated with genotype $4 \mathrm{HEV}$ to further identify the replication of HEV in the uterus. Notably, HEV RNA was persistently detectable in the cells for at least six passages (end of the experiment) with slowly increasing viral titer (Figure 2E). Meanwhile, the positive fluorescence signal of the HEV ORF2 capsid protein was observed in HEVinfected Hela cells at $48 \mathrm{~h}$ postinoculation, whereas no signal was found in uninfected mock cells (Figure 2F). These results strongly confirmed that HEV can replicate in the uterus.

\subsection{Decreased Fertility in HEV-Infected Female Mice}

HEV has been detected in infertile males with impaired sperm quality, and HEV infection causes pathological damage in the testis [36]. However, the HEV-induced impairment of reproduction in females is rarely evaluated. In the present study, each HEV-infected female mouse was separately copulated with at least three healthy adult male mice for 10 days. The body weight of female mice coupled with adult males were weighted every day after copulation (Supplementary Materials Figure S1), and the level of progesterone was determined at 5,8 , or 10 days post-copulation to decide whether the mouse was pregnant (Supplementary Materials Figure S2). After 10 days of copulation, all uninfected mock mice were found to be pregnant with a total of 48 fetuses. However, a significant reduction in pregnancy rates was found in HEV-infected mice at 17 (50\% pregnant, 2/4), 24 (0 pregnant, 0/4), and $31 \mathrm{dpi}(75 \%$ pregnant, 3/4) (Figure 3A). Moreover, the number of fetuses born to HEV-infected mothers also decreased; in particular, no fetuses were found in mice that were initially copulated at $14 \mathrm{dpi}$ (Figure 3A,E).

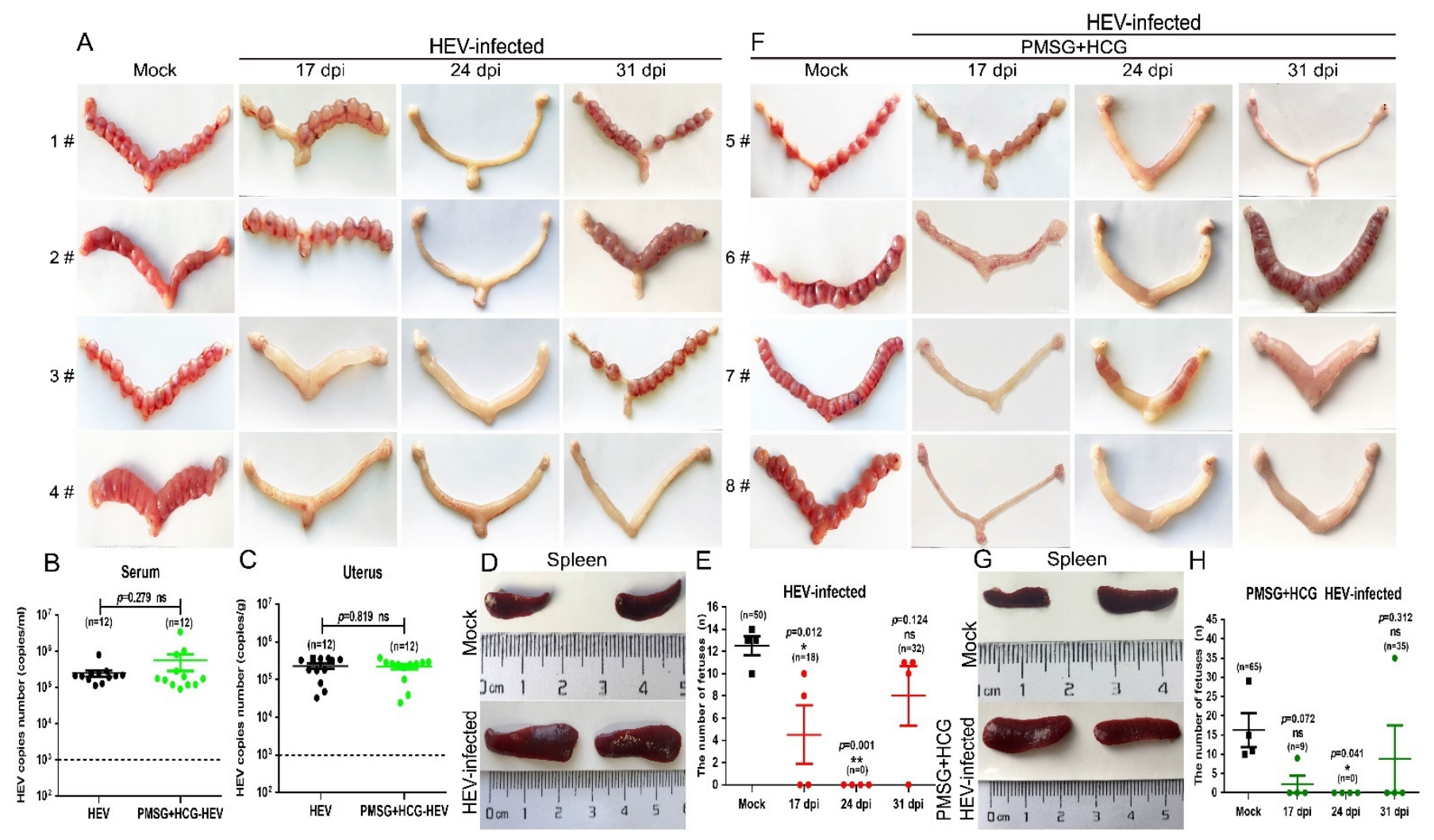

Figure 3. HEV infection results in decreased fertility in BALB/c female mice. (A) Morphological analysis of the uteruses from mock or HEV-infected mice at 17, 24, and 31 dpi (E 10). The copy numbers of HEV RNA in the serum (B) and uterus (C) of HEV-infected mice pretreated with or without PMSG and HCG were compared and analyzed by IBM SPSS Statistics 21 software. ${ }^{*} p<0.05 ;{ }^{* *} p<0.01$. (D) Sizes of spleens from mock or HEV-infected mothers. (E) Number of fetuses born to mock or HEV-infected mothers. (F) Morphological analysis of the uteruses from mock or HEV-infected mice synchronized with PMSG and HCG at 17, 24, and 31 dpi (E 10). (G) Sizes of spleens from mock or HEV-infected mothers who were synchronized with PMSG and HCG. (H) Number of fetuses born to mock or HEV-infected mothers who were synchronized with PMSG and HCG at 17, 24, and 31 dpi. Data were analyzed by IBM SPSS Statistics 21 software. ${ }^{*} p<0.05 ;{ }^{* *} p<0.01$. 
Mice were pretreated with PMSG for $24 \mathrm{~h}$ and then injected with HCG to exclude the influence of estrum on pregnancy. The treatment of PMSG and HCG affected neither the viral replication in serum and uterus (Figure 3B,C) nor the splenomegaly (Figure 3D,G). However, the pregnancy rates of the HEV-infected mice did not improve (Figure 3F). Although more fetuses (fetuses $=65$ ) were born to uninfected mock mice treated with PMSG and HCG than to mice in the untreated copulation control group (fetuses $=50$ ), HEV-infected mice still bore only a few fetuses ( 9 fetuses in the 17 dpi group, 0 fetuses in the 24 dpi group, and 35 fetuses in the 31 dpi group) (Figure 3F,H). The significant decrement in the number of fetuses caused by HEV infection has also been reported in HEV-infected rabbits [38]. Thus, whether HEV infection impairs female reproduction must be urgently investigated in the clinic.

3.3. HEV Infection Results in Uterine Endometrial Damages and Evokes Inflammatory Responses in the Uteruses of Mice That Miscarried

Infections with viruses, such as PRRSV and CVB3, have revealed that viral replication in the uterus is associated with tissue damage [22,23]. Endometrial thickness (EMT) is negatively related to the spontaneous abortion rate and ectopic pregnancy rate [39]. The EMT of HEV-infected mice that had experienced miscarriage was significantly thinner than that of the uninfected mock mice (Figure 4A,B) at 24 and 31 dpi. However, no significant difference was found in mice at $17 \mathrm{dpi}$. Meanwhile, loose myometrium, eosinophil infiltration, and significantly decrease endometrial glands were found in the HEV-infected miscarriage mice, especially in the mice in the 24 and 31 dpi groups (Figure $4 \mathrm{~A}, \mathrm{C}$ ). Clinical diseases, such as metritis, endometritis, and abortion, are well-known important causes of infertility [23].

HEV infection usually inflicts damage via severe inflammatory responses. Inflammation is more severe in HEV-infected chimpanzees than in HCV-infected ones [40]. Thus, the inflammatory responses in the uterus were determined to evaluate the injury caused by HEV infection. Interestingly, significant increases in CD45+ leukocytes and F4/80+ macrophages were observed in the uteruses of HEV-infected mice at 24 or 31 dpi (Figure 4D-G). Meanwhile, a large number of fluorescent apoptotic signals were detected in the uteruses of HEV-infected mice, especially in mice infected with HEV for 24 days (Figure $4 \mathrm{H}, \mathrm{I})$. Elevated inflammatory responses and extensive apoptosis should be responsible for endometrial injury. 


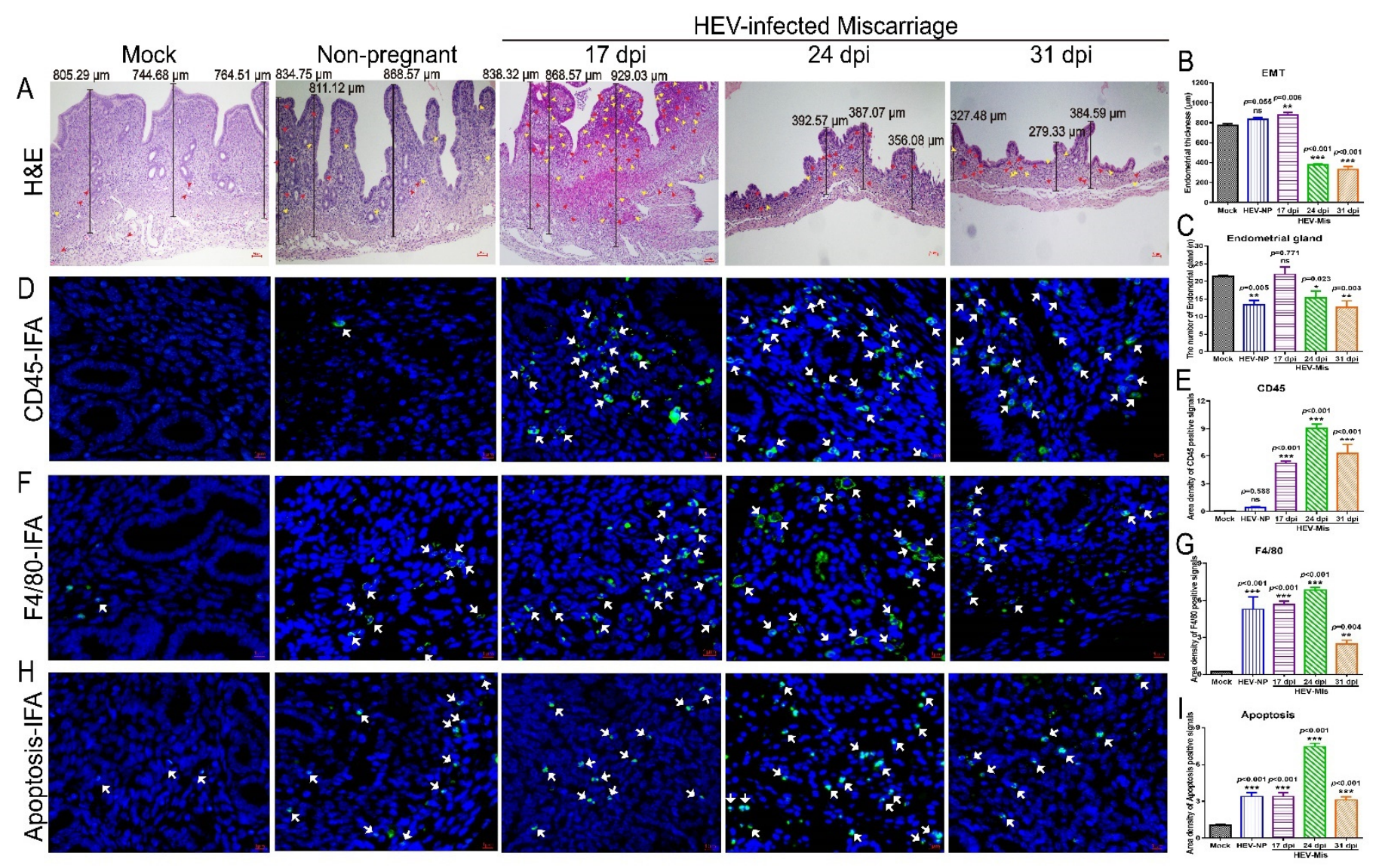

Figure 4. Uterine damages caused by HEV infection. (A) Histopathological analysis of uteruses from mock, HEV-infected nonpregnant, or HEV-infected miscarriage mice by H \& E staining. (B) The EMT was measured and compared with that of mock mice, HEV-infected nonpregnant, or HEV-infected miscarriage mice at 17, 24, and 31 dpi. (C) The number of endometrial glands was calculated and compared with that of mock mice, HEV-infected nonpregnant, or HEV-infected miscarriage mice at 17, 24, and 31 dpi. The presence of CD45+ leukocytes ((D), white arrow), F4/80+ macrophages ((F), white arrow), and apoptotic cells $((\mathbf{H})$, white arrow) in the uteruses of mice with or without HEV infection were separately identified by IFA. Positive fluorescent signals of CD45+ leukocytes (E), F4/80+ macrophages (G), and apoptotic cells (I) were separately calculated by Image-Pro Plus 6.0 software and analyzed with IBM SPSS Statistics 21 software. ${ }^{*} p<0.05$; ${ }^{* *} p<0.01 ;{ }^{* * *} p<0.001$.

\subsection{HEV Infection Causes Disordered Gene Expression in the Uteruses of Nonpregnant Mice}

Estrogen plays an important role in maintaining pregnancy by binding to estrogen receptors. HEV has been confirmed to inhibit the expression of estrogen receptors (ER- $\alpha$ and ER- $\beta$ ) in HEV-infected cells [16]. In the present study, IHC analysis revealed that ER- $\alpha$ was significantly suppressed in the uteruses of all HEV-infected mice, regardless of whether they were miscarried, nonpregnant (Figure 5A,B), or nonpregnant mice (Figure 6L,M). These results strongly suggested that HEV infection reduces ER expression. 


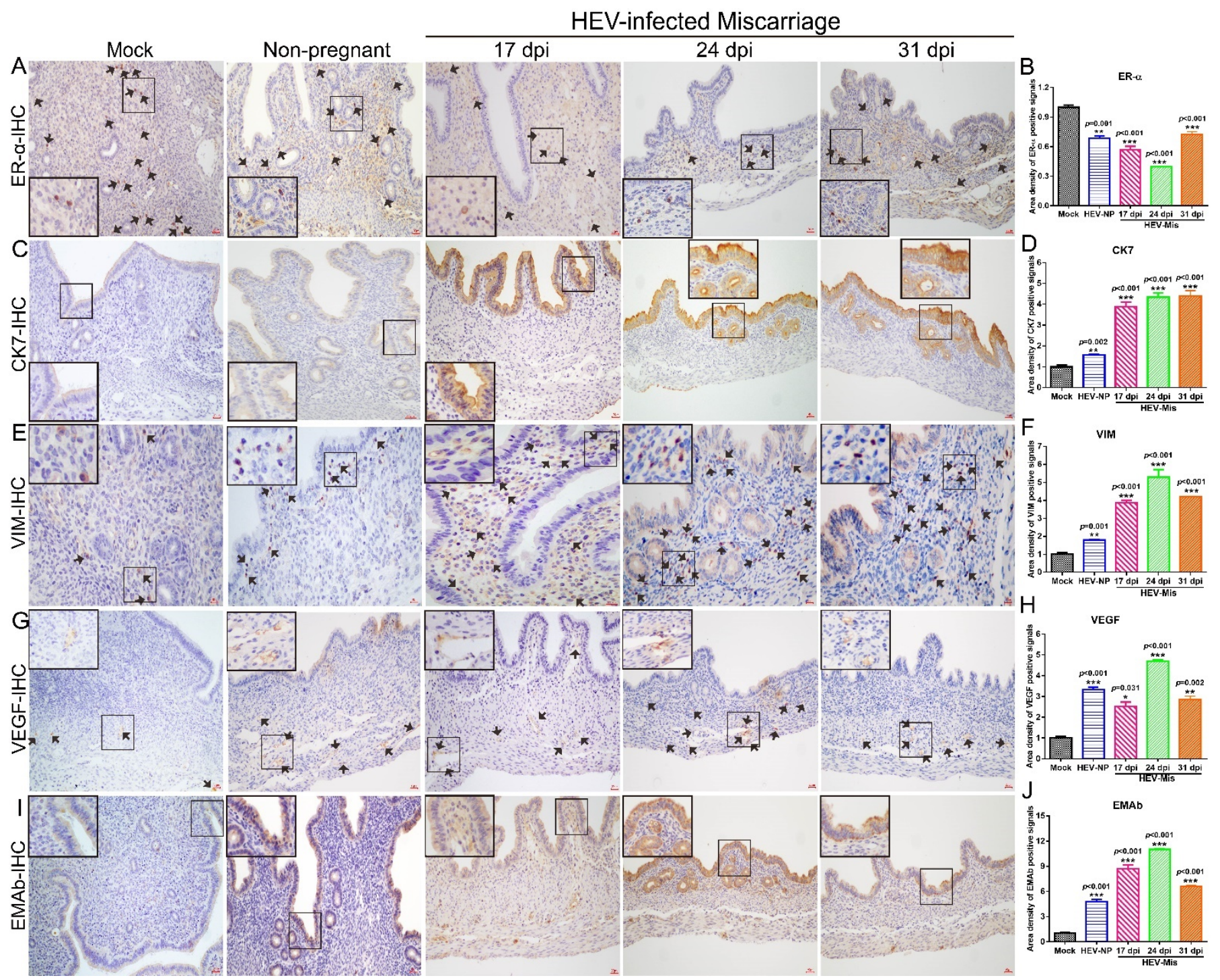

Figure 5. HEV infection causes gene disorders in mice that had miscarried. The expressions of ER- $\alpha$ (A), CK-7 (C), $\operatorname{VIM}(\mathbf{E}), \operatorname{VEGF}(\mathbf{G})$, and EMAb (I) in the uteruses of mock mice, HEV-infected nonpregnant mice, or HEV-infected mice that had miscarried at 17, 24, or 31 dpi were determined by IHC. Positive signals of ER $\alpha$ (B), CK7 (D), VIM (F), VEGF (H), and $\mathrm{EMAb}(\mathrm{J})$ in the uteruses of mock mice, HEV-infected nonpregnant mice, and HEV-infected miscarriage mice were separately calculated by Image-Pro Plus 6.0 software and compared by IBM SPSS Statistics 21 software. ${ }^{*} p<0.05 ;{ }^{* *} p<0.01$; $* * * p<0.001$. 

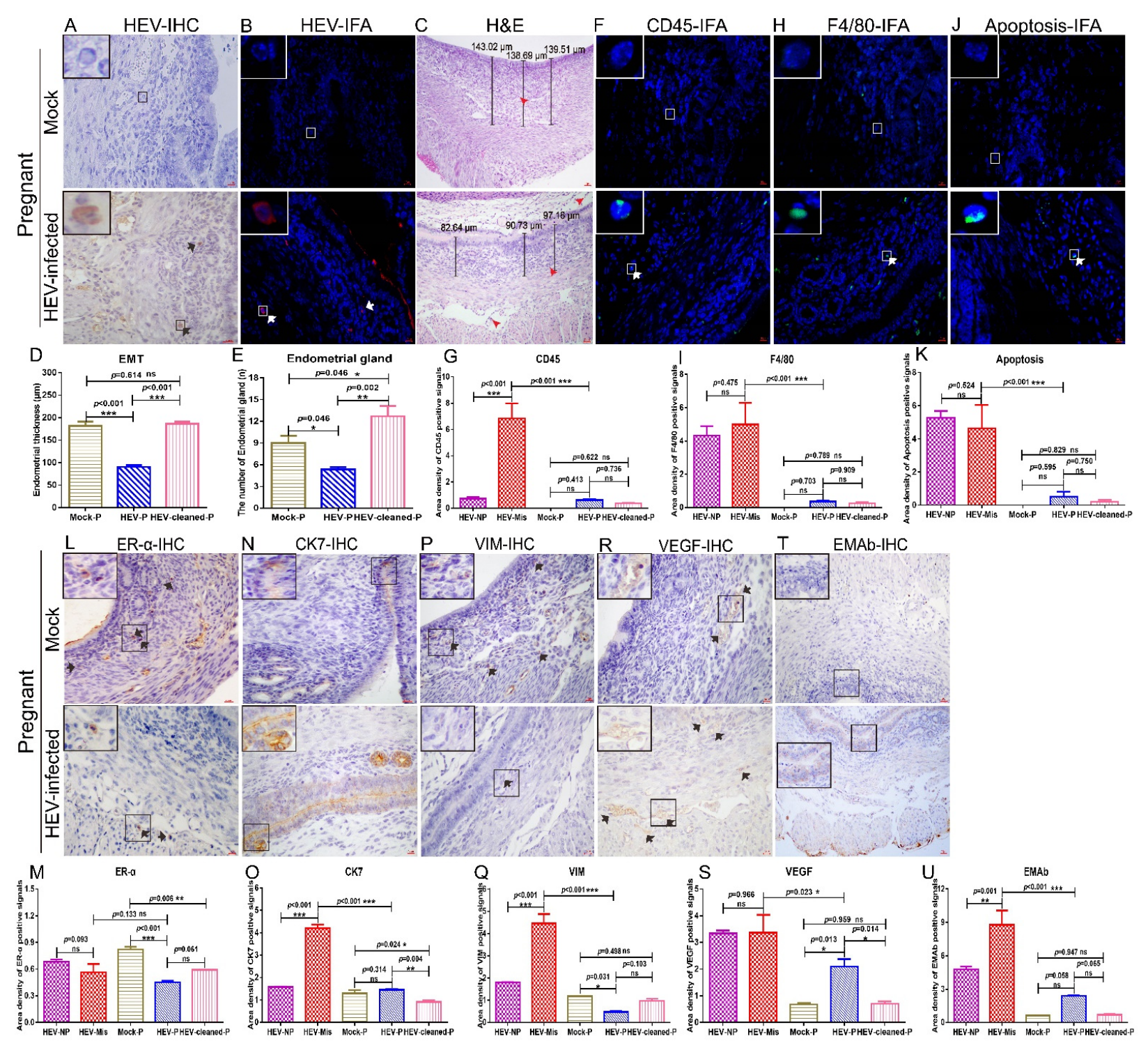

Figure 6. Uterine damages in HEV-infected pregnant mice are mild. HEV antigens were detected in the uteruses of mock or HEV-infected pregnant mice by IHC (A) and IFA (B). (C) H \& E analysis of uteruses from mock pregnant mice or HEV-infected pregnant mice. The presence of CD45 (F), F4/80 (H), and apoptotic cells (J) in the uteruses of mock pregnant mice or HEV-infected pregnant mice were identified by IFA. Nuclei were stained with DAPI. (D) The EMT of HEV-infected mice was measured and compared with that of mock pregnant, HEV-infected pregnant mice, or mice that became pregnant after HEV clearance. (E) The number of endometrial glands was calculated and compared with that of mock pregnant mice, HEV-infected pregnant mice, or mice that became pregnant after HEV clearance (E). Positive signals of CD45 (G), F4/80 (I), and apoptotic cells $(\mathbf{K})$ in the uteruses of mock pregnant mice, HEV-infected pregnant mice, and mice that became pregnant after HEV clearance were separately calculated by Image-Pro Plus 6.0 software and compared by IBM SPSS Statistics 21 software. ${ }^{*} p<0.05 ;{ }^{* *} p<0.01 ;{ }^{* *} p<0.001$. The expressions of ER $\alpha(\mathbf{L})$, CK7 (N), VIM (P), VEGF (R), and EMAb (T) in the uteruses of mock pregnant mice or HEV-infected pregnant mice were determined by IHC. Positive signals of ER $\alpha(\mathbf{M})$, CK7 (O), VIM (Q), VEGF (S), and EMAb (U) in the uteruses of mock pregnant mice, HEV-infected pregnant or nonpregnant mice, and mice that became pregnant after HEV clearance were separately calculated by Image-Pro Plus 6.0 software and compared by IBM SPSS Statistics 21 software. ${ }^{*} p<0.05 ;{ }^{* *} p<0.01 ;{ }^{* * *} p<0.001$.

The endometrium is one of the essential components of the uterus [41]. The physiological functions of the uterine endometrium (uterine lining) include preparation for implantation and pregnancy maintenance [42]. Cytokeratin-7 (CK7), an epithelial marker, is also an inflammatory indicator that transduces signals and participates in inflammation 
development [43]. The expression of CK7 is positively correlated with the pathological grade of cervical intraepithelial neoplasia [44,45]. Therefore, the expression level of CK7 in the uteruses of HEV-infected mice was determined by IHC. The results showed that CK7 expression in the uteruses of HEV-infected mice that had undergone miscarriage was significantly increased relative to that in uninfected mock mice (Figure 5C,D). Meanwhile, CK7 expression in HEV-infected mice that had experienced miscarriage was higher than that in HEV-infected pregnant mice or in mice after HEV clearance (Figure $6 \mathrm{~N}, \mathrm{O}$ ).

VIM, the most important intermediate fiber in mesenchymal cells, forms a network of cell scaffolds with microtubules and microfilaments to maintain the integrity of mesenchymal cells [46]. In addition, it is associated with various autoimmune diseases and organ transplantation immunity and has a nonspecific immune activation function that can promote inflammatory responses [47,48]. Interestingly, the expression of VIM in the uteruses of HEV-infected mice that had experienced miscarriage persistently increased relative to that in the uteruses of uninfected mock mice (Figure 5E,F). Similar to CK7, VIM was significantly expressed in HEV-infected mice that had miscarried relative to in HEV-infected pregnant mice (Figure $6 \mathrm{P}, \mathrm{Q}$ ).

VEGF is a vital angiogenesis factor that promotes the formation of new blood vessels [49]. The drastic increase in VEGF expression in patients infected with Helicobacter pylori suggests that VEGF expression is associated with inflammatory responses and persistent gastric mucosa injury [50]. In the present study, at 17, 24, or $31 \mathrm{dpi}$, VEGF expression in HEV-infected mice that had miscarried was distinctly activated (Figure 5G,H) relative to that in uninfected mock mice or HEV-infected pregnant mice (Figure 6R,S).

Abnormal autoimmune processes can affect reproduction at various stages. EMAb is an autoantibody that targets the endometrium and causes a series of immune responses. It can specifically bind to antigens, activate the complementary system, affect the implantation of fertilized eggs, and cause miscarriage [51]. EMAb levels are associated with the outcome of early threatened abortion. Therefore, the expression of EMAb in the uteruses of HEVinfected mice that had miscarried and pregnant mice were determined via IHC. Remarkably, EMAb was prominently expressed in mice that had experienced miscarriage (Figure 5I,J) relative to in uninfected mock mice or HEV-infected pregnant mice (Figure 6T,U). Taken together, the remarkably increased expression levels of CK7, VIM, VEGF, and EMAb and the prominent suppression of ER- $\alpha$ in the uteruses of HEV-infected mice that had miscarried than in uninfected mock mice or HEV-infected pregnant mice may contribute to unsuccessful pregnancies.

\subsection{HEV Infection Induces Moderate Uterine Damages in Pregnant Mice}

The HEV titer in the blood and uterus were quantified to understand why some HEVinfected mice could become pregnant, whereas others became sterile. Notably, serum viral titers did not significantly differ between pregnant mice and nonpregnant mice (Figure 2A). However, the viral titer in the uteruses of HEV-infected nonpregnant mice was significantly higher than that in the uteruses of HEV-infected pregnant mice (Figure 2B). These results strongly suggested that high viral titer in the uterus may be responsible for sterility. Although IHC and IFA revealed the presence of HEV antigens in the uteruses of HEV-infected pregnant mice (Figure 6A,B), the positive signals in these mice were weaker than those in mice that had miscarried (Figure 2C,D). However, the EMT of HEV-infected pregnant mice was significantly thinner than that of uninfected pregnant mice (Figure 6C,D). Histopathological analyses indicated that the uteruses of HEV-infected pregnant mice were infiltrated with few eosinophilic inflammation factors (Figure 6C). The EMT of HEV-infected pregnant mice was still significantly thinner than that of the uninfected mock pregnant mice or pregnant mice after complete HEV clearance (Figure 6C,D and Supplementary Materials Figure S3E). However, the number of endometrial glands in the uterus in HEVinfected pregnant mice did not significantly decrease compared with that in uninfected mock pregnant mice or mice that became pregnant after HEV clearance (Figure 6C,E and Supplementary Materials Figure S3E). Although sporadic CD45+ leukocytes (Figure 6F,G), 
F4/80+ macrophages (Figure 6H,I), and apoptotic cells (Figure 6J,K) were observed in the uteruses of HEV-infected pregnant mice, the number of positive cells in these groups of mice were significantly lower than that in HEV-infected mice that had experienced miscarriages (Figure 6G,I,K). These results indicated that the severe inflammatory responses in the uterus evoked by HEV infection may contribute to miscarriage. Furthermore, consistent with the results of our previous studies [16,52], IHC analysis revealed reduced ER- $\alpha$ expression in the uteruses of HEV-infected mice (Figure 6L,M). However, the expression levels of CK7, VIM, VEGF, and EMAb in the uteruses of HEV-infected pregnant mice were significantly lower than those in the uteruses of HEV-infected mice that had miscarried and were comparable with those in the uteruses of uninfected mock pregnant mice or pregnant mice after $\mathrm{HEV}$ clearance (Figure $6 \mathrm{~N}-\mathrm{U}$ ). Uterine damage in $\mathrm{HEV}$-infected pregnant mice was milder than that in HEV-infected mice that had miscarried.

\subsection{HEV-Induced Uterine Injury Can Be Eliminated}

Male genital tract damage caused by HEV infection can be partly recovered when the virus has been completely cleared from the body [4]. Given that HEV infection usually causes an acute disease, the recovery of the uterus after viral clearance was investigated. Female mice $(n=8)$ were coupled with healthy male mice $(n=8)$ to evaluate uterine injury after viral clearance. The existence of HEV antigens was excluded by IHC and IFA (Supplementary Materials Figure S3C,D). Mock-infected female mice $(n=4)$ were mated with normal male mice $(n=4)$ as the control. Interestingly, the mock and HEV-cleared mice were pregnant with a similar number of fetuses (48 fetuses in mock group vs. 46 fetuses in the HEV-cleared group [Supplementary Materials Figure S3A,B]). Pathological analysis indicated that the uteruses of HEV-cleared female mice lacked significant injury and had comparable EMT with those of mock mice (Supplementary Materials Figures S3E and S6D). Meanwhile, inflammatory responses were investigated in HEV-cleared pregnant mice. Notably, CD45+ leukocytes, F4/80+ macrophages, and apoptotic cells were very rare in the uteruses of HEV-cleared pregnant mice (Supplementary Materials Figures S3F-H and S6G,I,Q). Moreover, the expression levels of ER- $\alpha$, CK7, VIM, VEGF, and EMAb in HEVcleared pregnant mice were not significantly different from those in mock pregnant mice (Supplementary Materials Figures S3I-M and S6M,O,Q,S,U). These results indicated that the uterine damage caused by acute $\mathrm{HEV}$ infection can be recovered after complete HEV clearance.

\section{Discussion}

Although HEV infection usually produces acute and self-limiting diseases in the general population, it results in serious morbidity and mortality during pregnancy [53]. $\mathrm{HEV}$ infection during pregnancy causes adverse pregnancy outcomes, such as acute liver failure, FHF, hemorrhage, miscarriage, stillbirth, and preterm delivery [14]. Although HEV mainly replicates in the liver, multiple extrahepatic sites, such as the brain, spleen, intestines, kidney, muscles, and testes, have been reported [36,54-56]. In vitro studies using the decidua basalis and fetal placenta have found that HEV replicates in the human maternalfetal interface [12]. The presence of HEV RNA and antigens in the placenta, uterus, and ovaries indicates that HEV can replicate in the female reproductive system $[20,34,57,58]$. However, the exact pathogenesis of HEV during pregnancy remains to be defined.

Approximately 8-16\% of miscarriages occur in HEV-infected pregnant women [59,60]. Nevertheless, the pathogenesis of this condition is largely unknown. Pregnancy is a complex process for maintaining fetal development in the uterus. Any damage to the uterus caused by pathogen infection threatens the fetus [61]. BALB/c mice are sensitive to genotype $4 \mathrm{HEV}$ but dull to genotype $3 \mathrm{HEV}$, which only infects humanized mice $[62,63]$. Concerns have been raised about the adverse pregnancy outcomes caused by genotype 4 $\mathrm{HEV}$ infection. In the present study, genotype $4 \mathrm{HEV}$-infected BALB/c mice were used to explore the uterus damages caused by HEV infection. Notably, miscarriage or infertility was found in $58.33 \%$ (7/12) of HEV-infected mice. Worsened pregnancy outcomes were 
obtained in HEV-infected mice treated with PMSG and HCG for estrus synchronization, and only one mouse was found to be pregnant $(1 / 12)$. The serum concentration of progesterone first increased and then decreased strongly. This trend indicated that abortion was caused by HEV infection. The significant reduction in the number of fetuses at $24 \mathrm{dpi}$ also suggested adverse pregnancy outcomes during HEV infection. The comparable viral titers in the uterus and serum implied that HEV efficiently replicates in the uterus. Pathological analysis revealed an extremely thin EMT filled with $\mathrm{CD} 45^{+}$leukocytes and F4/80 macrophages. Apoptosis was significantly increased in the uteruses of HEV-infected nonpregnant mice from 17 to $30 \mathrm{dpi}$ (end of the experiment). Efficient viral replication in the uterus may have contributed to severe inflammation and cell apoptosis and then resulted in EMT damage, which is harmful to the maintenance of pregnancy. Interestingly, although no significant differences were observed among the serum viral titers of HEV-infected nonpregnant mice, mice that had miscarried, and pregnant mice, the viral titers in the uteruses of nonpregnant mice were significantly higher than those in pregnant mice. Meanwhile, although the EMT in HEV-infected pregnant mice appeared normal compared with that in uninfected mock pregnant mice, the EMT of HEV-infected nonpregnant mice, mice that had miscarried, and pregnant mice were all significantly thinner than that of uninfected mock mice. The impairment of the EMT and endometrial gland strongly suggested that HEV infection results in severe EMT damage. However, the EMT and endometrial gland recovered after complete HEV clearance, and normal pregnancy was observed. The results suggested that the EMT damage caused by HEV is responsible for the failure of pregnancy maintenance. In addition, inflammatory responses and cell apoptosis were significantly more severe in the uteruses of HEV-infected mice that had experienced miscarriage than in the uteruses of pregnant mice with or without HEV. This result further indicated that the serious impairment of EMT contributes to poor pregnancy outcomes.

HEV infection in the uterus may decrease uterine vitality and cause pathological damage. Moreover, the expression levels of ERAb, CK7, VIM, and VEGF were significantly increased in the uteruses of HEV-infected mice that had miscarried compared with those in the uteruses of HEV-infected pregnant mice. This outcome indicated that HEV infection promoted the expression of ERAb, CK7, VIM, and VEGF and accelerated adverse pregnancy outcomes. The inhibition of ER- $\alpha$ expression by HEV infection has been confirmed in pregnant women and HEV cell cultures [16,17]. In the present study, ER- $\alpha$ expression was significantly suppressed in the uteruses of HEV-infected pregnant mice or mice that had experienced miscarriage. The reduction in ER- $\alpha$ expression inhibited the phosphorylation of S6 in the PI3K-AKT-mTOR signaling pathway and subsequently increased HEV replication [18]. Our previous studies have shown that HEV infection regulates estrogen signaling pathways by inhibiting the cAMPK-PKA-CREB and PI3K-AKT-mTOR signaling pathways $[17,18]$. Thus, the dysregulation of genes in the uterus may be responsible for adverse pregnancy outcomes. Notably, worsened pregnancy outcomes were observed in HEV-infected mice treated with PMSG and HCG for estrus synchronization. Excess hormones may accelerate HEV replication and result in endocrine disorders. Thus, couples who are undergoing in vitro fertilization should be screened for HEV infection.

\section{Conclusions}

HEV replicates in the uterus and results in abortion and infertility. Severe injuries with significant EMT thinning, increased inflammatory responses, and aggravated apoptosis were found in the uteruses of HEV-infected mice that had experienced miscarriage. The suppression of ER- $\alpha$ expression and the increase in CK7, ERAb, VIM, and VEGF expression caused by HEV infection may contribute to adverse pregnancy outcomes. These findings have important implications for our understanding of the pathogenesis of HEV during pregnancy.

Supplementary Materials: The following are available online at https:/ /www.mdpi.com/article/10 .3390/v13101950/s1, Figure S1: The body weight changes in mock or HEV-infected female mice from 
mating for 10 days. Figure S2: The concentration of progesterone in mock or HEV infected female mice. Figure S3: Uterine environment of pregnant mice after HEV-clearance.

Author Contributions: Conceptualization, F.H. and W.Y. (Weimin Yang); Methodology, W.Y. (Weimin Yang) and S.C.; Software, W.Y. (Weimin Yang), H.K.M. and Z.Q.; Validation, C.C., Y.Z., Y.X. and L.X.; Formal Analysis, W.Y. (Weimin Yang) and T.L.; Investigation, W.Y. (Weimin Yang); Resources, S.C.; Data Curation, W.Y. (Weimin Yang); Writing-Original Draft Preparation, W.Y. (Weimin Yang); Writing_Review \& Editing, F.H.; Visualization, D.W.; Supervision, F.H.; Project Administration, F.H.; Funding Acquisition, D.W., F.H. and W.Y. (Wenhai Yu). All authors have read and agreed to the published version of the manuscript.

Funding: This research was funded by the National Natural Science Foundation of China (81960370), Natural Science Foundation of Yunnan province (2018FB132). Natural Science Foundation for Distinguished Young Scholars of Yunnan province (202001AV070005) and Yunnan Provincial Key Laboratory of Clinical Virology (202005AG070062-011). Program for Innovative Research Team (in Science and Technology) in University of Yunnan Province (2020). The Chinese Academy of Medical Sciences Innovation Fund for Medical Sciences (2019-I2M-1-004), Program for Cultivating Reserve Talents in Medical Disciplines from the Health Committee of Yunnan Province (H-2019043) and PUMC Youth Fund (3332019008). The APC was funded by Program for Innovative Research Team (in Science and Technology) in University of Yunnan Province (2020).

Institutional Review Board Statement: The study was conducted according to the guidelines of the Kunming University of Science and Technology, and approved by the Ethics Committee of Kunming University of Science and Technology (protocol code 2016JC012 and 1 March 2016).

Informed Consent Statement: Not applicable.

Data Availability Statement: The data that support the findings of this study are available within the article as well as in the supplementary files.

Acknowledgments: We thanks Chenchen Yang, Jianwen Situ, Yi Li and Xianhui Hao for their helps in animal model.

Conflicts of Interest: The authors did not report any potential conflicts of interest. Each author has confirmed compliance with the journal's requirements for authorship.

Ethical Statement: The authors confirm that the ethical policies of the journal, as noted on the journal's author guidelines page, have been adhered to. All operations were performed in accordance with the guidelines of the Kunming University of Science and Technology Animal Care and Use Committee.

\section{References}

1. Smith, D.B.; Simmonds, P.; Jameel, S.; Emerson, S.U.; Harrison, T.J.; Meng, X.J.; Okamoto, H.; Van der Poel, W.H.M.; Purdy, M.A. Consensus proposals for classification of the family Hepeviridae. J. Gen. Virol. 2014, 95 Pt 10, 2223-2232. [CrossRef]

2. Debing, Y.; Moradpour, D.; Neyts, J.; Gouttenoire, J. Update on Hepatitis E Virology: Implications for Clinical Practice. J. Hepatol. 2016, 65, 200-212. [CrossRef] [PubMed]

3. Bazerbachi, F.; Haffar, S. Acute fulminant vs. acute-on-chronic liver failure in hepatitis, E. diagnostic implications. Infect. Dis. Nor. 2014, 47, 112. [CrossRef] [PubMed]

4. Blasco-Perrin, H.; Abravanel, F.; Blasco-Baque, V.; Peron, J.M. Hepatitis, E. the neglected one. Liver Int. 2016, 36 (Suppl. 1), 130-134. [CrossRef] [PubMed]

5. Huang, F.; Li, Y.L.; Yu, W.H.; Jing, S.R.; Wang, J.; Long, F.Y.; He, Z.L.; Yang, C.C.; Bi, Y.H.; Cao, W.T.; et al. Excretion of Infectious Hepatitis E Virus Into Milk in Cows Imposes High Risks of Zoonosis. Hepatology 2016, 64, 350-359. [CrossRef]

6. Meng, X.J. Hepatitis E virus: Animal reservoirs and zoonotic risk. Vet. Microbiol. 2010, 140, 256-265. [CrossRef] [PubMed]

7. Tei, S.; Kitajima, N.; Takahashi, K.; Mishiro, S. Zoonotic transmission of hepatitis E virus from deer to human beings. Lancet 2003, 362, 371-373. [CrossRef]

8. Nelson, K.E.; Labrique, A.B.; Kmush, B.L. Epidemiology of Genotype 1 and 2 Hepatitis E Virus Infections. Cold Spring Harbor Perspect. Med. 2018, 9, a031732. [CrossRef]

9. Kumar, S.; Subhadra, S.; Singh, B.; Panda, B.K. Hepatitis E virus: The current scenario. Int. J. Infect. Dis. 2013, 17, E228-E233. [CrossRef]

10. Pérez-Gracia, M.T.; Suay-García, B.; Mateos-Lindemann, M.L. Hepatitis E and pregnancy: Current state. Rev. Med. Virol. 2017, 27, e1929. [CrossRef] 
11. Shinde, N.; Patil, T.; Deshpande, A.; Gulhane, R.; Patil, M.; Bansod, Y. Clinical profile, maternal and fetal outcomes of acute hepatitis e in pregnancy. Ann. Med. Health Sci. Res. 2014, 4, 133-139.

12. Gouilly, J.; Chen, Q.; Siewiera, J.; Cartron, G.; Levy, C.; Dubois, M.; Al-Daccak, R.; Izopet, J.; Jabrane-Ferrat, N.; El Costa, H. Genotype specific pathogenicity of hepatitis E virus at the human maternal-fetal interface. Nat. Commun. 2018, 9, 4748. [CrossRef] [PubMed]

13. Jeblaoui, A.; Haim-Boukobza, S.; Marchadier, E.; Mokhtari, C.; Roque-Afonso, A.M. Genotype 4 Hepatitis E Virus in France: An Autochthonous Infection with a More Severe Presentation. Clin. Infect. Dis. 2013, 57, E122-E126. [CrossRef]

14. Li, M.Y.; Bu, Q.N.; Gong, W.Y.; Li, H.M.; Wang, L.; Li, S.S.; Sridhar, S.; Woo, P.C.Y.; Wang, L. Hepatitis E virus infection and its associated adverse feto-maternal outcomes among pregnant women in Qinhuangdao, China. J. Matern. Fetal Neonatal Med. 2020, 33, 3647-3651. [CrossRef] [PubMed]

15. Zhang, J. Nursing care of 20 cases pregnant women infected with Hepatitis E virus. Yiyao Qianyan 2015, 14, 238-239. (In Chinese)

16. Bi, Y.H.; Yang, C.C.; Yu, W.H.; Zhao, X.C.; Zhao, C.C.; He, Z.L.; Jing, S.R.; Wang, H.X.; Huang, F. Pregnancy serum facilitates hepatitis E virus replication in vitro. J. Gen. Virol. 2015, 96, 1055-1061. [CrossRef]

17. Wu, J.; Huang, F.; Ling, Z.X.; Liu, S.C.; Liu, J.; Fan, J.; Yu, J.; Wang, W.; Jin, X.Y.; Meng, Y.L.; et al. Altered faecal microbiota on the expression of Th cells responses in the exacerbation of patients with hepatitis E infection. J. Viral. Hepat. 2020, 27, 1243-1252. [CrossRef]

18. Gong, S.L.; Hao, X.H.; Bi, Y.H.; Yang, C.C.; Wang, W.J.; Mickael, H.K.; Zhang, Y.K.; Chen, S.F.; Qian, Z.Y.; Huang, F.; et al. Hepatitis E viral infection regulates estrogen signaling pathways: Inhibition of the cAMPK-PKA-CREB and PI3K-AKT-mTOR signaling pathways. J. Med. Virol. 2021, 93, 3769-3778. [CrossRef]

19. Bose, P.D.; Das, B.C.; Kumar, A.; Gondal, R.; Kumar, D.; Kar, P. High viral load and deregulation of the progesterone receptor signaling pathway: Association with Hepatitis E-related poor pregnancy outcome. J. Hepatol. 2011, 54, 1107-1113. [CrossRef]

20. Yu, W.H.; Hao, X.H.; Li, Y.; Yang, C.C.; Li, Y.L.; He, Z.L.; Huang, F. Vertical transmission of hepatitis E virus in pregnant rhesus macaques. Sci. Rep. Uk 2020, 10, 17517. [CrossRef]

21. Khuroo, M.S.; Kamili, S.; Jameel, S. Vertical transmission of hepatitis E virus. Lancet 1995, 345, 1025-1026. [CrossRef]

22. Sharma, S.; Kumar, A.; Kar, P.; Agarwal, S.; Ramji, S.; Husain, S.A.; Prasad, S.; Sharma, S. Risk factors for vertical transmission of hepatitis E virus infection. J. Viral. Hepat. 2017, 24, 1067-1075. [CrossRef] [PubMed]

23. Turner, M.L.; Healey, G.D.; Sheldon, I.M. Immunity and Inflammation in the Uterus. Reprod. Domest. Anim. 2012, 47, 402-409. [CrossRef]

24. Wira, C.R.; Fahey, J.V.; Sentman, C.L.; Pioli, P.A.; Shen, L. Innate and adaptive immunity in female genital tract: Cellular responses and interactions. Immunol. Rev. 2005, 206, 306-335. [CrossRef] [PubMed]

25. Jabbour, H.N.; Sales, K.J.; Catalano, R.D.; Norman, J.E. Inflammatory pathways in female reproductive health and disease. Reproduction 2009, 138, 903-919. [CrossRef]

26. Sheldon, I.M.; Cronin, J.; Goetze, L.; Donofrio, G.; Schuberth, H.J. Defining Postpartum Uterine Disease and the Mechanisms of Infection and Immunity in the Female Reproductive Tract in Cattle. Biol. Reprod. 2009, 81, 1025-1032. [CrossRef]

27. Mor, G.; Cardenas, I. The Immune System in Pregnancy: A Unique Complexity. Am. J. Reprod. Immunol. 2010, 63, 425-433. [CrossRef]

28. Karniychuk, U.U.; Nauwynck, H.J. Pathogenesis and prevention of placental and transplacental porcine reproductive and respiratory syndrome virus infection. Vet. Res. 2013, 44, 95. [CrossRef]

29. Young, H.J.; Kyung Min, L.; Hwa, K.Y.; Hye Min, S.; Young Kyung, B.; Jung Hye, H.; Hosun, P. Pregnancy loss following coxsackievirus b3 infection in mice during early gestation due to high expression of coxsackievirus-adenovirus receptor (CAR) in uterus and embryo. Exp. Anim. 2014, 63, 63-72.

30. Xiong, Y.Q.; Mo, Y.; Luo, Q.M.; Huo, S.T.; He, W.Q.; Chen, Q. The Risk of Human Papillomavirus Infection for Spontaneous Abortion, Spontaneous Preterm Birth, and Pregnancy Rate of Assisted Reproductive Technologies: A Systematic Review and Meta-Analysis. Gynecol. Obstet. Investig. 2018, 83, 417-427. [CrossRef]

31. Shi, T.L.; Huang, L.J.; Xiong, Y.Q.; Zhong, Y.Y.; Yang, J.J.; Fu, T.; Lei, X.F.; Chen, Q. The risk of herpes simplex virus and human cytomegalovirus infection during pregnancy upon adverse pregnancy outcomes: A meta-analysis. J. Clin. Virol. Off. Publ. Pan Am. Soc. Clin. Virol. 2018, 104, 48-55. [CrossRef] [PubMed]

32. Weisblum, Y.; Panet, A.; Zakay-Rones, Z.; Vitenshtein, A.; Haimov-Kochman, R.; Goldman-Wohl, D.; Oiknine-Djian, E.; Yamin, R.; Meir, K.; Amsalem, H.; et al. Human cytomegalovirus induces a distinct innate immune response in the maternal-fetal interface. Virology 2015, 485, 289-296. [CrossRef] [PubMed]

33. Weisblum, Y.; Oiknine-Djian, E.; Vorontsov, O.M.; Haimov-Kochman, R.; Zakay-Rones, Z.; Meir, K.; Shveiky, D.; Elgavish, S.; Nevo, Y.; Roseman, M.; et al. Zika Virus Infects Early- and Midgestation Human Maternal Decidual Tissues, Inducing Distinct Innate Tissue Responses in the Maternal-Fetal Interface. J. Virol. 2017, 91, e01905-16. [CrossRef] [PubMed]

34. Yang, C.C.; Hao, X.H.; Li, Y.L.; Long, F.Y.; He, Q.X.; Huang, F.; Yu, W.H. Successful Establishment of Hepatitis E Virus Infection in Pregnant BALB/c Mice. Viruses 2019, 11, 451. [CrossRef] [PubMed]

35. Baylis, S.A.; Blumel, J.; Mizusawa, S.; Matsubayashi, K.; Sakata, H.; Okada, Y.; Nubling, C.M.; Hanschmann, K.M. World Health Organization International Standard to harmonize assays for detection of hepatitis E virus RNA. Emerg. Infect. Dis. 2013, 19, 729-735. [CrossRef] 
36. Huang, F.; Long, F.; Yu, W.; Situ, J.; Fu, L.; He, Z.; Dong, H.; Yang, C.; Li, Y.; Yang, F.; et al. High prevalence of hepatitis E virus in semen of infertile male and causes testis damage. Gut 2018, 67, 1199-1201. [CrossRef]

37. Domino, M.; Domino, K.; Gajewski, Z. An application of higher order multivariate cumulants in modelling of myoelectrical activity of porcine uterus during early pregnancy. Biosystems 2019, 175, 30-38. [CrossRef]

38. Ahn, H.S.; Han, S.H.; Kim, Y.H.; Park, B.J.; Kim, D.H.; Lee, J.B.; Park, S.Y.; Song, C.S.; Lee, S.W.; Choi, C. Adverse fetal outcomes in pregnant rabbits experimentally infected with rabbit hepatitis E virus. Virology 2017, 512, 187. [CrossRef]

39. Rui, F.; Cai, L.; Fang, X.; Jie, C.; Yang, W.; Xin, Z. The effect of endometrial thickness on the day of hCG administration on pregnancy outcome in the first fresh IVF/ICSI cycle. Gynecol. Endocrinol. 2016, 32, 473-476.

40. Claro, Y.; Denali, B.; Mcdonald, S.L.; Myers, T.G.; Keiko, T.; Hanh, N.; Engle, R.E.; Sugantha, G.; Emerson, S.U.; Purcell, R.H. Pathogenesis of hepatitis E virus and hepatitis C virus in chimpanzees: Similarities and differences. J. Virol. 2010, 84, 11264-11278.

41. Azizi, R.; Aghebati-Maleki, L.; Nouri, M.; Marofi, F.; Negargar, S.; Yousefi, M. Stem cell therapy in Asherman syndrome and thin endometrium: Stem cell- based therapy. Biomed Pharm. 2018, 102, 333-343. [CrossRef]

42. Critchley, H.O.D.; Maybin, J.A.; Armstrong, G.M.; Williams, A.R.W. Physiology of the Endometrium and Regulation of Menstruation. Physiol. Rev. 2020, 100, 1149-1179. [CrossRef]

43. Liang, T.; Qiang, L.; Haozhen, R.; Bing, C.; Xianglin, H.; Lingjun, M.; Siqiao, Z.; Jianxin, Z.; Xitai, S.; Jianwu, D. Repair of extrahepatic bile duct defect using a collagen patch in a Swine model. Artif. Organs 2015, 39, 352-360.

44. Lee, H.; Lee, H.; Cho, Y.K. Cytokeratin7 and cytokeratin19 expression in high grade cervical intraepithelial neoplasm and squamous cell carcinoma and their possible association in cervical carcinogenesis. Diagn. Pathol. 2017, 12, 18. [CrossRef] [PubMed]

45. Saad, R.S.; Mashhour, M.; Noftech-Mozes, S.; Ismiil, N.; Dube, V.; Ghorab, Z.; Faragalla, H.; Khalifa, M.A. P16INK4a expression in undifferentiated carcinoma of the uterus does not exclude its endometrial origin. Int. J. Gynecol. Pathol. 2012, 31, 57-65. [CrossRef] [PubMed]

46. Pranab, D.; Jyoti, T.; Suvradeep, M. Intermediate filament: Structure, function, and applications in cytology. Diagn. Cytopathol. 2014, 42, 628-635.

47. Mor-Vaknin, N.; Punturieri, A.; Sitwala, K.; Markovitz, D.M. Vimentin is secreted by activated macrophages. Nat. Cell Biol. 2003, 5, 59-63. [CrossRef] [PubMed]

48. Bargagna-Mohan, P.; Deokule, S.P.; Thompson, K.; Wizeman, J.; Srinivasan, C.; Vooturi, S.; Kompella, U.B.; Mohan, R. Withaferin A Effectively Targets Soluble Vimentin in the Glaucoma Filtration Surgical Model of Fibrosis. PLoS ONE 2013, 8, e63881.

49. Claessonwelsh, L. Blood vessels as targets in tumor therapy. Upsala J. Med. Sci. 2012, 117, 178-186. [CrossRef]

50. Soomro, M.H.; Shi, R.; She, R.; Yang, Y.; Hu, F.; Li, H.; Ayan, A. Antigen detection and apoptosis in Mongolian gerbil's kidney experimentally intraperitoneally infected by swine Hepatitis E virus. Virus Res. 2016, 213, 343-352. [CrossRef]

51. Qi, Y.H.; Fang, L. Clinical study on treatment of endometriosis-related infertility patients by laparpscopic surgery in combination of Quyu Jiedu recipe. Zhongguo Zhong Xi Yi Jie He Za Zhi Zhongguo Zhongxiyi Jiehe Zazhi Chin. J. Integr. Tradit. West. Med./Zhongguo Zhong Xi Yi Jie He Xue Hui Zhongguo Zhong Yi Yan Jiu Yuan Zhu Ban 2011, 31, 892-895.

52. Yang, C.; Yu, W.; Bi, Y.; Long, F.; Li, Y.; Wei, D.; Hao, X.; Situ, J.; Zhao, Y.; Huang, F. Increased oestradiol in hepatitis E virus-infected pregnant women promotes viral replication. J. Viral Hepat. 2018, 25, 742-751. [CrossRef]

53. Sébastien, L.; Olivier, M.; Florence, A.; Sabine, C.-R.; Nassim, K.; Jacques, I. Hepatitis E Pathogenesis. Viruses $2016,8,212$.

54. Pischke, S.; Hartl, J.; Pas, S.D.; Lohse, A.W.; Jacobs, B.C.; Van der Eijk, A.A. Hepatitis E virus: Infection beyond the liver? J. Hepatol. 2017, 66, 1082-1095. [CrossRef]

55. Kamar, N.; Marion, O.; Abravanel, F.; Izopet, J.; Dalton, H.R. Extrahepatic manifestations of hepatitis E virus. Liver Int. Off. J. Int. Assoc. Study Liver 2016, 36, 467-472. [CrossRef] [PubMed]

56. Kamar, N.; Abravanel, F.; Lhomme, S.; Rostaing, L.; Izopet, J. Hepatitis E virus: Chronic infection, extra-hepatic manifestations, and treatment. Clin. Res. Hepatol. Gastroenterol. 2015, 39, 20-27. [CrossRef]

57. Bose, P.D.; Das, B.C.; Hazam, R.K.; Kumar, A.; Medhi, S.; Kar, P. Evidence of extrahepatic replication of hepatitis E virus in human placenta. J. Gen. Virol. 2014, 95, 1266-1271. [CrossRef] [PubMed]

58. An, J.; Liu, T.; She, R.; Wu, Q.; Tian, J.; Shi, R.; Hao, W.; Ren, X.; Yue, Y.; Lu, Y. Replication of hepatitis E virus in the ovary and promotion of oocyte apoptosis in rabbits infected with HEV-4. Oncotarget 2018, 9, 4475-4484. [CrossRef]

59. Krain, L.J.; Atwell, J.E.; Nelson, K.E.; Labrique, A.B. Fetal and Neonatal Health Consequences of Vertically Transmitted Hepatitis E Virus Infection. Am. J. Trop. Med. Hyg. 2014, 90, 365. [CrossRef] [PubMed]

60. Patra, Sharda: Maternal and Fetal Outcomes in Pregnant Women with Acute Hepatitis E Virus Infection. Ann. Intern. Med. 2007, 147, 28. [CrossRef]

61. Locksmith, G.; Duff, P. Infection, antibiotics, and preterm delivery. Semin. Perinatol. 2001, 25, 295-309. [CrossRef] [PubMed]

62. Allweiss, L.; Gass, S.; Giersch, K.; Groth, A.; Kah, J.; Volz, T.; Rapp, G.; Schobel, A.; Lohse, A.W.; Polywka, S.; et al. Human liver chimeric mice as a new model of chronic hepatitis E virus infection and preclinical drug evaluation. J. Hepatol. 2016, 64, 1033-1040. [CrossRef] [PubMed]

63. Sayed, I.M.; Foquet, L.; Verhoye, L.; Abravanel, F.; Farhoudi, A.; Leroux-Roels, G.; Izopet, J.; Meuleman, P. Transmission of hepatitis E virus infection to human-liver chimeric FRG mice using patient plasma. Antivir. Res. 2017, 141, 150-154. [CrossRef] [PubMed] 